\title{
"Aprendi com as primaveras a deixar-me cortar e voltar sempre inteira": o caso de Frank
}

\author{
"I learned from springs to let myself be cut and always come back in one \\ piece": the case of Frank. \\ DAIANY LARA MASSIAS LOPES SGRINHOLI ${ }^{1}$ / THIAGO SITONI GONÇALVES²
}

Resumo: O presente relato de experiência objetiva apresentar o caso de uma usuária com diagnóstico de depressão e ansiedade que ao solicitar o Centro de Psicologia Aplicada (CPA) da Universidade Paranaense (UNIPAR), apresenta a demanda de ressignificar seu projeto de ser frente às situações-problema de seu cotidiano. A luz da fenomenologia existencial de Sartre e Beauvoir, respalda-se a análise de seu caso, pela compreensão do diagnóstico com a constituição do seu existir, construída dialeticamente, corpo-mente, história-singularidade, produto-produtor de seu meio e de si mesmo. A estrutura do relato busca seguir o método regressivo-progressivo fundamentado por Sartre, a fim de elucidar os (des)encontros entre o passado com a sua realidade atual e, a partir disso, promover uma consciência reflexiva e ressignificação do seu projeto de ser.

Palavras-chave: Sartre. Método progressivo-regressivo. Projeto de ser. Psicologia clínica.

Abstract: The present experience report aims to present the case of a user diagnosed with depression and anxiety who, upon requesting the Center for Applied Psychology (CPA) of the Universidade Paranaense (UNIPAR), presents the demand to reframe her project of being in face of problem situations of your daily life. In the light of Sartre and Beauvoir's existential phenomenology, the analysis of his case is supported by the understanding of the diagnosis with the constitution of his existence, dialectically constructed, body-mind, historysingularity, product-producer of his environment and of himself same. The structure of the report seeks to follow the regressive-progressive method founded by Sartre, in order to elucidate the (dis) encounters between the past and its current reality and, from there, promote a reflective awareness and reframing of its project of being.

Keywords: Sartre. Progressive-regressive metod. Project of being. Clinical psychology.

\section{Introdução}

Este trabalho manifesta a vivência do estagiário a partir do Estágio Supervisionado Curricular Obrigatório Específico I (ESCO) do curso de Psicologia da Universidade Paranaense (UNIPAR), com ênfase em processos clínicos, ocorrido ao longo do ano de 2019. O principal objetivo do estágio na formação psi, é desenvolver habilidades e competências com a prática entrelaçada à teoria, integrando o/a acadêmico/a em múltiplos contextos e intervenções.

\footnotetext{
'Psicóloga formada pela Universidade Paranaense (UNIPAR), Psicoterapeuta especialista em Psicologia fenomenológico-existencial pela Universidade Paranaense (UNIPAR), Mestranda em Promoção da Saúde (UNICESUMAR). E-mail: daianylara@prof.unipar.br

2 Psicólogo formado pela Universidade Paranaense (UNIPAR) e mestrando em Filosofia pela UNIOESTE. E-mail: thiagositonipsi@gmail.com
} 
“Aprendi com as primaveras a deixar-me cortar e voltar sempre inteira”: o caso de Frank

Com base nisso, o projeto norteador da prática clínica, intitulou-se "Psicoterapia individual para adultos: a clínica sob a perspectiva fenomenológica-existencial na contemporaneidade", pautado no atendimento individual de adultos solicitantes do serviço da clínica-escola Centro de Psicologia Aplicada (CPA) dessa universidade. A dinâmica dos atendimentos acontecia semanalmente, com a duração de cinquenta minutos cada sessão, em conjunto com quatro horas de orientação supervisionada.

A linha teórica que alicerçou o curso dos atendimentos, das orientações e a presente teorização do caso clínico é a abordagem fenomenológico-existencial, fundamentada pela filosofia existencial e no método fenomenológico, de Jean-Paul Sartre, embasando a díade teoria-prática. Posteriormente, o método e os conceitos principais de sua filosofia, serão explanados para a compreensão do caso, a partir do próprio autor e de seus comentadores.

Em vista desses aspectos, o caso amparador para a gênese deste trabalho é o de Frank $^{3}$, que iniciou uma triagem interventiva em 2018 e retorna ao atendimento psicoterápico no ano de 2019, no início do segundo bimestre, cuja queixa, em um primeiro momento, está atrelada ao seu diagnóstico de depressão e ansiedade junto com a necessidade de refazer-se profissionalmente e lidar com situações problema atreladas ao seu cotidiano.

Vale esclarecer que desde o início do desenvolvimento do atendimento e de teorização do caso, não se atentou para definições nosológicas da sintomatologia desses dois transtornos de humor, tendo em vista a atitude de não rotular o sujeito em sofrimento a um determinado diagnóstico a priori e de aniquilar a liberdade de ser diante de sua situação.

Para delimitar o caminho teórico traçado a partir deste caso, o próximo tópico debruça-se a explanar acerca do método, o andamento das orientações e os seus objetivos disparadores pelo projeto de estágio. Em um terceiro momento, será descrito o caso, a partir de algumas informações que contornam os motivos do usuário a solicitar o serviço psicológico, uma breve observação geral de sua história de vida e as suas principais queixas, levantadas por uma triagem interventiva realizada nas primeiras quatro sessões e no transcorrer dos encontros em setting, totalizando em vinte e três atendimentos.

Em seguida, o tópico que versa sobre as discussões será responsável por fazer as conexões para a compreensão entre a narrativa enunciada pela usuária e a teoria existencialista sartriana, com as intervenções realizadas, visando aproximar-se da experiência vivida (do fenômeno) e do projeto de ser, a partir de suas escolhas reflexivas ou não.

\footnotetext{
${ }^{3} \mathrm{O}$ nome utilizado nesse relato para dirigir-se ao usuário solicitante do serviço psicoterápico é fictício, visando preservar sua identidade, respaldado pela resolução o1o/o5 que regulamenta o Código de Ética Profissional do Psicólogo que, legitima o sigilo profissional pelo seu 9o artigo (CFP, 2014)
} 


\section{Metodologia}

Os atendimentos aconteciam semanalmente, às quartas-feiras e/ou quintasfeiras, uma hora cada sessão e paralelo à isso, foram realizados orientações com a professora orientadora às terças-feiras, com a duração de quatro horas, com o objetivo de discutir casos, entrecruzar as vivências do estagiário com a teoria, proporcionar uma compreensão dos conceitos e aplicar os conhecimentos da fenomenologia existencial em psicoterapia individual, o que contribuiu para o desenvolvimento pessoal e profissional do estagiário enquanto profissional da Psicologia no âmbito da clínica individual.

O contexto de estágio é o Centro de Psicologia Aplicada (CPA), um serviçoescola de atendimento psicológico da Universidade Paranaense. Os recursos que foram utilizados enquanto disparadores de temáticas e reflexões, selecionados ao longo do processo orientação-prática, foram duas dinâmicas e um recurso literário.

A primeira dinâmica utilizada é baseada nos escritos de Tereza Cristina S. Erthal (1998), intitulada Cadeira Vazia, cujo o objetivo é aprender a lidar com o conflito, o que geralmente não é visto como algo necessário, por vezes, pejorativo e que nos tira de uma pseudo harmonia do convívio social. Com isto posto, a dinâmica funciona da seguinte maneira: uma cadeira é colocada na frente da pessoa. Ela pode representar um conflito intrapessoal ou interpessoal. A partir disso, é incentivado um diálogo vivido pela usuária, com as partes em conflito, apontando medos, angústias, questões, visando um equilíbrio. $\mathrm{O}$ conflito vem, principalmente, para questionar o fazer-se no mundo da usuária com o outro e consigo mesma.

A segunda dinâmica caracteriza-se como A Dinâmica do Quadrado, cujo o objetivo é de reconhecer o enfrentamento da usuária em relação às suas verdades e a sua própria construção subjetiva que é interferida por várias facticidades, inclusive, o outro. Essa atividade acontece da seguinte forma: é solicitado que ela escolha um espaço do setting enquanto pertencente a si, e nesse fragmento espacial em que se encontra, é definido como seu. O terapeuta tentará utilizar de seus recursos para adentrar ao seu espaço, usando estratégias que visam interferir no seu espaço.

Outro recurso usado em setting é o livro $A$ parte que falta do autor Shel Silverstein (1976/2018), narrando o trajeto de uma pequena bola que lhe faltava uma parte e por isso, não se considerava feliz. A partir desse desconforto, o protagonista se dispõe a rolar, indo à procura de sua parte faltante, enfrentando vários percalços ao longo do caminho, lidando com a presença e a ausência de sentido de vida.

Pelas primeiras três sessões, foram realizadas a demarcação da triagem para mapear as primeiras informações relativas à história de vida da usuária. Nesses encontros, ela relata estar atualmente residindo com o seu parceiro, sobrinha, mãe e simultaneamente com a família de seu companheiro em um sobrado. Interposto ao encaminhamento de seu psiquiatra, vem à psicoterapia como alternativa de amparo 
e, por consequência, fortalecimento diante da manifestação sintomática do diagnóstico de depressão e ansiedade. Fazia uso do medicamento Clonazepam ${ }^{4}$ hà três anos com acompanhamento de seu psiquiatra. Em relação ao convívio familiar, a usuária menciona um vínculo próximo e significativo com a mãe e a sobrinha e por outro lado, um convívio conflituoso com a sogra. Em vista de suas expectativas, enxergava na psicoterapia uma oportunidade de refletir em formas de enfrentamento das situações-problema de seu cotidiano e pela necessidade de ressignificar o seu projeto profissional

Com base nisso, as hipóteses levantadas em seis sessões, foram relacionadas a uma extrema dificuldade em lidar com as vicissitudes de sua situação em casa, uma exigência exacerbada diante do retorno ao mercado de trabalho, tanto do INSS quanto de si própria, e uma atitude continente em relação aos conflitos próprios e dos outros cuja compreensão necessitava acontecer a luz de sua história de vida.

O percurso que objetivou descortinar o fenômeno, isto é, o que surgiu pelo trajeto de Frank, é conceituado como método regressivo-progressivo (Cf. SILVA, 2020). Uma das comentadores acerca do método utilizado por Sartre, Freitas (2018) conceitua-o como movimento dialético, ou seja, a característica de remontar o que precede a realidade atual, a seguir, esclarecer, em vista de abranger novas possibilidades contidas na situação presente e, a partir de um futuro, traçar o projeto, colocando no existir o possível e o vir a ser, isto é, o que ainda não se fez possível.

Schneider (2008), ao desenvolver a respeito do método, pontua enquanto seu objeto crucial de investigação, a biografia, pois, ela é o aspecto concreto da vida do existente humano, cuja práxis em psicoterápica se debruça por compreender os sentidos dos seus atos, gestos, sentimentos, que possuem contornos significativos e fazem parte do seu projeto, pois, existir é isso: um processo ininterrupto de ressignificar sentidos.

Dado ao entendimento de que o outro fala de si, ou seja, ele é artífice de sua própria existência, é no encontro que o método acontece, por meio da descrição dos seus problemas. Em contato com a sua autobiografia em par com o seu presente, redimensiona-se o existente humano enquanto produto e produtor de seu meio, e a partir disso, busca-se alternativas em par com o que ele irá fazer com o que fizeram dele por meio de conceitos existenciais como, angústia, vazio, projeto de ser, liberdade, responsabilidade, e inclusive, uma leitura de psicopatologia (SCHNEIDER, 2009a; SCHNEIDER, 2008b; ERTHAL, 1998; VACCARO, 2014).

\footnotetext{
${ }^{4}$ Nome científico do medicamento relatado e comercialmente conhecido como Rivotril. Clonazepam é um anticonvulsivante e ansiolítico da série farmacológica dos benzodiazepínicos cuja principal função é a inibição do funcionamento do sistema nervoso central (SNC), permitindo uma ação de efeito tranquilizador.
} 


\section{Método progressivo-regressivo de Jean-Paul Sartre}

A inquietação diante da subserviência do existente humano em seu contexto histórico, foi o que movimentou a expressiva produção bibliográfica de Sartre para pensar o existir humano (FREITAS, 2018). É com base nesse filósofo, que a concepção de que nada anterior à realidade humana, nem uma moral ou natureza determina o sujeito, que o existencialismo se fundamenta. Sartre (1946/2014) esclarece que o existente humano é o único ser que precisa existir primeiro, em um mundo, para fazer sua essência a partir de sua escolha e responsabilidade por aquilo que fizer de si em uma dimensão ética.

A liberdade de ser como brotamento originário (Silva, 2018) é a característica ontológica do humano, pela qual há o rompimento de Sartre com modelos deterministas a priori que visam explicitar o sujeito. Vaccaro (2014), uma de suas comentadoras, escreve que, ao nascer, o homem é inserido em uma materialidade, em um contexto histórico, social, econômico, político, familiar e, ao passo em que se relaciona com estas instâncias, irá fazer-se enquanto realidade humana. Estas instituições não o definem. O sujeito somente é, a partir do momento em que está lançado no mundo e engajado em seu contexto histórico.

A noção de sujeito sartriano parte da concepção ser-em-si-ser-para-si, isto é, de um sujeito psicofísico, todo corpo e todo mente, entendido a partir de uma relação homem-mundo que acontece pela intencionalidade, isto é, que escapa em direção ao concreto, atribuindo contornos, significados pelo existente humano em sua experiência no mundo a partir de uma consciência vazia, que não coincide consigo mesma (VACCARO, 2014).

Desta forma, a constituição do sujeito se enlaça pela ação na concretude do existir, na realidade objetivada, considerando as facticidades, que são os factos, as coisas que acontecem e não escolhemos, as resistências, limitações, visto que a liberdade está em todas as situações possíveis, pois, é pela liberdade que há a ação. Nela, a realidade humana age a fim de projetar-se para novos possíveis (SILVA; VACCARO, 2016)

Erthal (1998) respaldada em uma abordagem existencial em psicoterapia, fundamenta como objetivo, descortinar o projeto original do cliente, isto é, as escolhas e ações advindas dele e não daquilo que os outros o designaram. Projeto e temporalidade caminham juntos no pensamento sartriano. De acordo com Alvim e Castro (2015) tempo é escoamento, ou seja, horizontal, fluxo e por isso transborda a noção que isola passado, presente e futuro.

Acerca do tempo, Vaccaro (2014) fundamenta que, o passado compõe aquilo que não é posto que, não somos a mesma pessoa de quatro anos atrás e nem poderemos retornar, pois está acabado, é um Em-si. O futuro torna-se aquilo que ainda não é, um possível, indeterminado. Por sua vez, há um presente que é ação, lançamento a este 
“Aprendi com as primaveras a deixar-me cortar e voltar sempre inteira": o caso de Frank

futuro, podendo reconfigurar esse projeto escolhido no passado, ressignificando no presente. Contudo, esse lançar-se, não nos dá garantias de afirmar se aquilo será de fato quem seremos.

Freitas (2018) comenta sobre o método que subsidia a apreensão da experiência humana no mundo. Inspirado em Lefebvre, Sartre faz uso da lógica dialética para a construção do conhecimento. Na contramão de uma lógica dicotômica entre vida e o saber, a lógica dialética atém-se primeiro à realidade (ao aqui e agora) para articular o pensamento, ou seja, ver o que a realidade foi, voltando ao passado, reconhecendo a historicidade de suas relações de produção, os sentidos construídos e após isso, transformá-la. Isso é o conhecimento: nunca fechado, sempre em aberto, em constante transformação.

Erthal (1998) emprega esse método para a construção do conhecimento em prática psicoterápica. $\mathrm{O}$ método progressivo-regressivo é visto enquanto práxis, pois, é uma união de saber e fazer que assume um posicionamento filosófico para embasar as vivências que se desvelam na clínica. De ordem existencialista, ela compreende a realidade humana por meio da experiência desvelada pelo fenômeno.

Schneider (2008) explica que é pela história de vida da realidade humana que se debruça essa práxis em psicoterapia, avizinhando-se das significações atribuídas ao longo de seus desdobramentos, de suas escolhas, a fim de realizar a mediação entre a criação do seu mundo e de si mesmo. O objetivo é ir retirando as camadas, detectando questões, até chegar no projeto original e para isso, o sujeito precisa desfazer-se daquilo que fizeram dele e fazer-se novamente.

Segundo Erthal (1998), é um processo criativo e de intenso contato com a angústia de ser e por vezes, de defrontar-se com a má-fé, que se caracteriza pelo momento de mistificação da realidade ao depositar a responsabilidade de ser e de escolher ao outro, isentando-se do ato de escolher enquanto ser-no-mundo.

Por meio da redução fenomenológica, isto é, da suspensão, um conceito advindo de Husserl, pode-se evidenciar o conteúdo concreto da vida autenticamente pela atitude de colocar em parênteses os nossos juízos de valores e significações morais. Em outras palavras, pode-se desvelar o fenômeno mediante um olhar dedicado à realidade do cliente, que é alteridade, ou seja, que se mostra diferente das construções pessoais do terapeuta iniciante (ERTHAL, 1998; MENDES; GRESSLER; FREITAS, 2012).

Com base nisso, o trajeto teórico a ser desenvolvido no tópico a seguir é circunscrito a partir de uma noção de clínica contemporânea fundamentada por Alvim e Castro (2015), baseado em um saber e fazer psi, que é contrário a uma ação mecanicista frente sociedade e seus fenômenos, a luz do engajamento, da compreensão e problematização da existência humana em sua realidade, em vista da sua capacidade de fazer-se sujeito em um mundo dado sócio historicamente, a partir 
de uma práxis pautada na transformação. Para isso, faz-se uso do conceito de situação, teorizado por Sartre (1943/2015) enquanto um conjunto de limites que caracterizam a existência, tal sendo meu lugar, meu passado, meus arredores, meu próximo e minha morte.

O primeiro tópico é definido pelo espaço ou contexto revelado à realidade humana, seja seu país, sua residência ou cidade, devido à impossibilidade humana de não estar em um espaço, habitando no vácuo espacial. Por exemplo, Sartre (1943/2015) manifesta que, ao nascer-se, ocupa-se um espaço determinado e a partir dali, há a possibilidade de escolher outros lugares originais, isto é, que dizem respeito ao projeto da realidade humana e também à liberdade situada frente a um conjunto de regras que o lugar possui. Então, pode-se reconhecer o lugar a partir de duas óticas:

[...] captar meu lugar como obstáculo intransponível e usar simplesmente de subterfúgio para defini-lo indiretamente no mundo; no segundo caso, ao contrário, os obstáculos não mais existirão, meu lugar não será um ponto de fixação, mas um ponto de partida (SARTRE, 1943/2015, p. 609).

Com isso, o segundo tópico, meu passado, diz respeito à força do que foi vivido para subsidiar o presente e preludiar o futuro, jamais determinando-o. O passado não determina as ações do homem no mundo, visto que já está posto e não podemos modificá-lo, mas, é com base no vivido que tomamos uma decisão, podendo ressignificar a partir de um presente ou continuar a repetir. Ora, o passado somente toma contornos de sentido se for levado em conta o futuro, pois, para que haja um alicerce de possibilidades, é necessário um passado, seja ele, como expressa Sartre (1943/2015 p. 614): "Passado vivo, passado semimorto, sobrevivências, ambiguidades, antinomias: o conjunto dessas camadas de preteridade é organizado pela unidade de meu projeto".

No terceiro tópico, antagônico ao primeiro, meus arredores, caracterizam-se pelos objetos, utensílios que circundam a realidade humana em seu projeto, podendo ser motivos para abandoná-lo ou para fortificar a sua realização. Para Sartre (1943/2015) somos ser-livre-para-mudar e este termo manifesta a característica de poder exercer a ação humana frente às coisas que existem independentes de minha existência, podendo apreender os arredores como obstáculos à percorrer ou ferramentas, objetos a serem utilizados ao seu favor.

No quarto tópico, caracteriza-se como o meu próximo ou o outro, que não se refere somente aos outros que esbarro no mundo, cujo projeto e liberdade também estão em relação (ou conflito) com os meus, todavia, refere-se aos utensílios e as coisas que já possuem significado antes de serem atribuídos por mim, sejam os imperativos ilustrados pelos sinais de trânsito (ex: pare, semáforos, placas, etc), as linguagens, gírias e dialetos nas quais precisa-se ter propriedade e que, repercutem no projeto existencial (Sartre, 1943/2015). 
Por último, Sartre (1943/2015) desenvolve sobre minha morte, caracterizando-a como o encerramento da existência enquanto para-si, impossibilitando a concretização de projetos e totalizando o existente humano em condição de em-si. $\mathrm{O}$ fenômeno da morte sobrecai no indeterminado que se deve levar em conta, pois, esperar por ela, para Sartre (1943/2015) é preparar-se em vão para o caráter inelutável do fim enquanto facticidade. Enquanto fenômeno, a morte manifesta o outro como vitorioso, pois, as memórias são as únicas formas de manter um contato com aquele que se foi. Sendo assim, as metamorfoses da vida ocorrem pelo outro vivente, podendo manter a memória do outro morto pelo diálogo entre os familiares ou amigos e/ou generalizando-a, desembocando como mais uma morte dentre tantas ao redor mundo.

Com base na delineação das características da situação, o próximo tópico versa em fazer o entrecruzamento de informações teóricas e vivenciais manifestadas pelo encontro terapêutico e conceitual, cujo objetivo é desvelar a experiência da usuária com os seus conflitos e as intervenções psi realizadas a partir delas.

\section{Alguns questionamentos anteriores ao caso: como desbravar a história de Frank?}

Baseado na explanação do método utilizado, torna-se imprescindível nesse tópico que haja uma aproximação com o caso de Frank. A sua solicitação por atendimento psicoterápico veio por encaminhamento de seu psiquiatra para maior cuidado com o seu diagnóstico de depressão e ansiedade. $\mathrm{O}$ acompanhamento psicoterápico realizou quando Frank passou por um procedimento de cirurgia bariátrica a dois anos atrás e após esse evento, veio à clínica-escola para uma triagem interventiva. A usuária pontua, nessas vinte e três sessões, os acontecimentos de sua vida que antecedem o diagnóstico de depressão e ansiedade, como a sua relação com o seu companheiro de vida, seu trabalho, seu passado (envolvendo um pouco de sua infância e adolescência), seu fazer-se mulher e sua busca por novos projetos.

Com isto posto, os tópicos seguintes versam em detalhar a história de vida de Frank, a partir das suas situações, ou seja, dos conjunto de limitações que fazem parte da existência que desvelam (im)possibilidades da continuidade do projeto, do seu vir a ser, caracterizado pelo lugar, pelo corpo, passado, pela posição, sua relação com o outro e com a morte. A situação se forma entre a liberdade e a facticidade, para-si e em-si, como uma síntese, cuja concepção é a liberdade de projetar-se para fora e nas contingências do cotidiano. (Alvim \& Castro, 2015).

\section{Primeiras sessões e a caracterização da sua biografia}

Neste tópico, debruça-se no enredamento da vida de Frank. Em seus trinta e sete anos de idade, F. solicita a psicoterapia tendo em vista o seu tratamento de depressão e ansiedade, acompanhado com psiquiatra a quatro anos. Levando em 
conta a dinâmica de sua família, na infância, F. relata ser a irmã do meio de mais dois irmãos homens. Sua mãe diz que ela é a filha que nasceu de parto natural e não deu tanto trabalho, em relação aos outros dois irmãos. O irmão mais velho, hoje casado, mantém pouco contato e o irmão mais novo, hoje, apresenta-se distante devido à sua dependência química. Ambos na infância, não eram próximos dela e eram apáticos em relação aos acontecimentos em casa. F. viveu de perto o definhamento da relação dos pais, gerado pela traição do pai e a passividade de sua mãe, em uma espera de mudança do marido, em troca de reconciliação e reconstrução do casamento. Avizinhando-se desse cenário, F. constata que essa espera foi em vão.

A situação de traição, segundo o seu relato, era vista com indiferença aos olhos dos irmãos e ainda, pelos parentes de seu pai, era tido como algo normal, naturalizado e esperado pelos padrões machistas seguidos na época. Em relação ao lugar onde moravam, encontravam-se distante da cidade, primeiro nos fundos da casa de sua avó paterna e depois, mudaram-se para uma chácara, onde por vezes, F. percebia a passagem de outras mulheres em casa.

Desde pequena, foi muito falante e inquieta diante das situações. Inquieta com a situação de traição de seu pai, pedia à mãe a separação, pela tortura em ver a tristeza no semblante de sua mãe. No ímpeto de silenciar a filha, a mãe pede para ela não falar mais sobre isso. Aos poucos, F. foi sendo silenciada, pelos irmãos que não faziam nada, pelo pai que trabalhava, sustentava a casa e justificava as traições dado a insatisfação sexual no casamento, pelas brigas que escutava escondida na porta do quarto e suas queixas não atendidas. Não desejava dar mais trabalho à mãe, que segundo ela, já tinha muitos conflitos pendentes.

Era espectadora de outros conflitos: via a mãe ser maltratada e humilhada pela sogra diversas vezes em casa. Incomodada com isso, tentava reagir (em vão) à todos os xingamentos de sua avó paterna para sua mãe. Nesse mesmo lugar, pôde conviver com o seu avô, que devido a um câncer, teve poucos dias ao seu lado e morreu serenamente. Também conheceu sua avó materna, mas pouco se sabe sobre ela. Pela mãe de F. sabe-se que houve uma reconciliação após o seu nascimento e então, ela vem visitá-la no seu terceiro aniversário. Sua avó materna vem a falecer dois anos depois de AVC.

Na adolescência, descreve-se como alguém que não gostava de muitas conversas, mais gorda do que as outras meninas de sua escola, ensimesmada e cujo contato com outras pessoas não era tão prazeroso, pois, o novo despertava medo, não era passível de controle. Sua voz começa a ganhar mais intensidade quando teve seu primeiro trabalho na mercearia de seu pai, aos dezoito anos e lá, descobriu que falar com o outro não era tão difícil assim. Sua relação com o pai era próxima, por mais que soubesse das suas traições. Em contrapartida, ele era a imagem do herói para F., que ao mesmo tempo em que ensinava sobre humildade e respeito ao outro, era o vilão devido ao machismo que cultivava. 
A voz de F. toma maior intensidade no seu primeiro casamento com John, com quem viveu durante quatro anos, vindo a falecer após um período de quatro semanas em um hospital, com uma gripe que impedia a continuidade de sua vida.

John foi o primeiro marido de F. Ao seu lado, experienciou sonhos, conflitos e também uma vivência conflituosa do marido com sua mãe, neste caso, sua sogra, que mesmo nos internamentos e no último dia da existência de John não esteve presente. F. relata com indignação que John foi o primeiro grande amor de sua vida que teve que se despedir para a morte. F. questionou o sentido de perder o seu amor dessa forma, questionou o seu Sagrado e toda sua relação com a finitude. No sepultamento, a mãe de John aparece, e então, expressa a perda escandalosamente, chamando a atenção de todos. F., enraivecida, pede silêncio à mãe e respeito ao seu luto, dizendo que aquelas lágrimas não trariam seu filho de volta, muito menos, o que ela deixou de ter feito enquanto mãe.

Seis meses após o falecimento de John, F. sente a proximidade da depressão. As paredes pareciam engoli-la. Ela relata como se fosse um buraco negro, que estava presente em seu peito, girando, cheio de dor, perpassando por todos os músculos de seu corpo e retirando toda a energia para continuar a existir. Nesse momento, F. relata pesar 120 quilos e começa a ter dificuldades para o seu autocuidado, experiência muito cansaço em fazer atividades cotidianas e em enfrentar as implicações sociais em estar obesa, devido aos estigmas que viveu todas as vezes que desejava comprar uma roupa, calçado, sair com os amigos, cruzar as pernas e que, ainda, implicou em sérios problemas de saúde, principalmente na coluna e no coração.

F. relata a sua experiência de desistência, que se manifestou como a anedonia, que significa a incapacidade de sentir prazer e ver sentido em continuar vivendo. Amedrontada pelo sintoma de batimentos acelerados, aparentando ser uma possível doença cardíaca, F. vai até o pronto atendimento. Ao relatar para o médico o seu estado de saúde e toda a história envolvida, o médico atribui o diagnóstico de depressão. F. frustra-se. Começa a tomar doses altas de Clonazepam e calmantes para dormir. Sente um medo gigantesco da dor aniquilar a sua vida, então, como alternativa para findar a dor, planeja o suicídio. O minuto decisor para não prosseguir com a tentativa de suicídio foi o impacto que isso geraria à mãe, desvelando um prolongamento de sofrimento à ela e implicando no maior julgamento dos outros ao redor, que já julgavam o comportamento de F.

Em agosto de 2017, F. consegue realizar uma cirurgia bariátrica, custeada pelo Sistema Único de Saúde e amparada no pós-operatório pelos seus pais, sendo um divisor de caminhos em sua vida. Devido à sérios problemas cardíacos, após o episódio com o psiquiatra, F. teve início de AVC e precisou ser internada às pressas. A bariátrica naquele momento foi a escolha mais assertiva, segundo F., para melhorar a sua qualidade de vida e, também, reconhecer-se em um corpo que era verdadeiramente dela. 
Em 2018, vários acontecimentos surgiram sucessivamente na vida de F. e por volta dessa época, percebeu a necessidade de ajuda profissional e do surgimento do que ela entende como depressão e ansiedade. Na mesma semana, seu pai decide expulsar sua mãe de casa, quando ela vem realizar um tratamento oftalmológico na sua cidade, pois decide assumir um relacionamento com a amante. Além disso, o pai deixa claro que não deseja lembrar que um dia teve filhos. O pai abandona $\mathrm{F}$. e sua mãe no portão de sua casa e segue seu novo projeto.

F., nessa mesma semana tinha decidido ir morar em outro país, tendo em vista um novo relacionamento, entretanto, Clark, o seu antigo parceiro, pede reconciliação. Sua mãe, idosa e diabética vem morar em sua casa com alguns pertences que $\mathrm{F}$. consegue trazer da casa de seu pai. Em seguida, por um telefonema, sua sobrinha pede socorro dizendo ter sido vítima de abuso pelo padrasto, o que movimentou F. e seu parceiro para agir. Em meio a tantas intensidades, Frank pede afastamento do seu trabalho, por verificar que o serviço que desempenhava não correspondia às relações ali existentes, não condizentes com os seus valores.

Em meio ao seu afastamento, seu pai fica sabendo da fragilidade de F. por outrem e o máximo de contato que tem é uma troca de olhares no portão de sua casa. Ele pede à mãe que cuide de sua filha e retorna à sua cidade para a sua esposa. Em meio à essa turbulência, F. tenta o suicídio, porém, é resgatada pelo seu companheiro a tempo. Na busca de "ocupar a cabeça" (sic), traçar recomeços, inicia a procurar outras alternativas de emprego. Amparada pelo INSS a três anos, F. lança-se em cursos de cortes de cabelo de vários perfis, pintura capilar, manicure e pedicure, todos voltados ao segmento da cosmética e estética. Todavia, F. reconhece que estar nos cursos não é uma tarefa fácil e além disso, estar amparada por uma autarquia da previdência social implica na constante fiscalização para o retorno ao mercado de trabalho, na qual ainda se sente muito vulnerável.

Estar nos cursos, em recomeço, com todos aqueles novos equipamentos, com outras pessoas de diversos níveis de conhecimento sobre a temática, professores desmotivadores e a expectativa de querer mudar de vida, repercutiram nas suas vivências, no seu novo projeto. Além disso, hoje vive nos cômodos de baixo da casa de sua sogra, cuja relação é baseada em uma não aceitação total do relacionamento de F. e Clark, pois sua sogra, pelo enunciado por F., não admite ver o filho junto à outra mulher que a ama e também que ele escolheu para viver. F. relata esse imenso cansaço e medo do que irá acontecer, e ainda, medo de posicionar-se, de falar, mesmo reconhecendo que engolir aquilo que está na ponta da sua língua movimentado pelo desejo de falar, é silenciado e desvela sofrimento e adoecimento.

F. solicita a psicoterapia como uma alternativa complementar ao acompanhamento psiquiátrico que realiza ao longo desses três anos de afastamento de seu trabalho. Além disso, solicita o serviço de atendimento psicológico para falar sobre depressão, ansiedade e sua história de vida, expressar e problematizar as 
“Aprendi com as primaveras a deixar-me cortar e voltar sempre inteira”: o caso de Frank

dificuldades de relacionamento com a sogra, falar não para as pessoas e em se posicionar diante do que deseja para a própria vida. A psicoterapia vem como uma oportunidade de refletir em formas de enfrentamento das situações-problema de seu cotidiano e pela necessidade de ressignificar o seu projeto profissional

\section{Resultados e discussões}

Acerca do "lugar" em sua infância, aquém de sua livre escolha, caracterizado por F. a partir da primeira à quarta sessão, evidencia-se um ambiente repleto de conflitos advindos de um contexto familiar, caracterizado por brigas entre os pais devido à infidelidade por parte paterna, adversidades intrafamiliares e uma construção de valores que correspondem aos moldes do patriarcado. Beauvoir (1949/2016) ampara na caracterização desse patriarcado, ao demarcar a mulher enquanto sujeito objetivado pela boca do patriarcado no transcorrer da história, cujo slogan é obediência e respeito. A simetria entre casamento e prostituição, cuja diferença está na durabilidade do contrato, também é relatado pela usuária, quando conta das traições consentidas e apoiadas pelos familiares no transcorrer de 40 anos.

F. desvela a experiência do seu sofrer enquanto criança, ao recordar-se do choro da mãe dentro do quarto, das paredes da antiga casa, os móveis, as cores das paredes, que delineavam ali um projeto da mãe em transformar uma relação tóxica para ambas as partes, pensando na relação díade, entre F. e sua mãe. Além disso, seus pais fundaram uma mercearia e foram morar em uma chácara afastada da cidade. Nesse período de tempo, a história brasileira é marcada pela censura, pelos decretos inconstitucionais (AI) da ditadura militar, por uma efervescência da população na luta por eleições diretas em meio ao autoritarismo, cerceamento de liberdade civil e de direitos humanos. Nesta época, o lugar não é visto como ponto de partida, mas, enquanto limitador do desdobramento de um projeto de ser original.

Devido ao lugar, em sua infância e adolescência, F. relata ser a espectadora (e não a protagonista) que, tal como a etimologia da palavra define, observou passivamente a sua situação e, nesse caso, sofre diante das adversidades vividas pela mãe que acreditava poder mudar seu marido apesar das traições e ao mesmo tempo, cria uma imagem ilusória de um pai herói devido às condições que ele provinha como moradia, alimentação e ensinamentos. Tal imagem é fortificada durante todo o período citado de sua vida.

Evidencia-se, nessa época, os seus próximos. F. depara-se ao nascer com uma relação matrimonial de seus pais com um sentido já estabelecido por eles, que atravessa histórica e subjetivamente o seu existir. Mesmo sabendo da infidelidade e da dor na relação de seus pais, F. expressa que eles continuavam a ensinar-lhe questões morais e ela prosseguia assentindo. Conviveu com a avó paterna, que corroborou com violências à sua mãe, sendo discursivas ou apoiando a atitude do filho (no caso, seu pai) com as suas amantes transitando pela casa. Na tentativa de 
agir, F. apela a mãe por um possível divórcio, mas, sua mãe pede a ela que se silencie, pois, assuntos como este, não servem às crianças5. Por muito tempo, Frank se colocou nesse lugar de silenciada a partir do outro: poucas relações, convívio apenas com alguns integrantes da família e o seu desejo de agir diante desse entrave fica em inércia.

Em psicoterapia, essas memórias vieram à luz quando a usuária viu a necessidade de defrontar-se com sua história de vida e com o sofrimento que vivenciou em seu passado, que por vezes, ao tentar relatar à mãe ou ao atual parceiro, era podada ou não levada à sério. Esse sofrimento reverberou em F. todas as vezes em que seu pai tentava manter contato em seu adultescer e principalmente, a partir da sétima sessão, que surge o pedido de divórcio após 40 anos, consentido pela mãe e negligenciado pelo pai. Ao fazer nexo com esses eventos de sua vida, F. entra em contato com a consciência reflexiva, que para Sartre (1943/2015) caracteriza-se por dar-se conta das repetições e alienações existenciais a partir da compreensão da experiência humana no mundo. Isto é, a mãe e a filha reagiram frente hà anos de violência e apequenamento de suas linhas subjetivas de vida e reconhecer isso, para F., tornou-se impulsionador de seu projeto de ser mulher hoje.

Ainda, caracterizando sua biografia pelos seus próximos e seus arredores, F. relata desde a adolescência ter sido gorda comparada às meninas de sua idade e isso, intensificou-se na vida adulta, a ponto de ter realizado uma cirurgia bariátrica a dois anos atrás devido às condições de saúde que se agravaram, desvelando inícios de infarto. Com isso, F. olha para o seu corpo como sobrevivente de várias vicissitudes, cravado pelas marcas cirúrgicas do procedimento. Marcas que significam para F., a sua tentativa de viver com maior qualidade de vida apesar dos riscos advindos da bariátrica. A usuária defronta-se com a angústia todas as vezes que relata um sofrimento de seu passado, reiterando a inevitabilidade em escolher e de fazer-se ainda que machucada. (Sartre, 1943/2015)

O método cirúrgico abriu-se para F. como ferramenta a seu favor. Isso significa que, as sobras de pele, estrias e cicatrizes foram traços remanescentes de seu passado que não correspondem mais ao seu presente, resquícios de um projeto que não correspondiam mais aos seus objetivos. Campos, Ferreira, Carvalho, Kraemer \& Seixas (2016) tecem a crítica de que o corpo obeso é alvo de uma construção discursiva baseado na Medicina enquanto saber legitimador de violência, ou seja, essa área do saber que, não somente opera em seu campo específico, mas, também produz discursos, normas e em nome de um padrão de saúde, violenta outros corpos.

Na pele, F. sentiu todas as formas de humilhação apontada pelo outro, e por vezes, tentou reagir, outras vezes, de tanto tentar, cansou-se. Pela cirurgia, F.

\footnotetext{
${ }^{5}$ Nesse tópico, é de grande valia ressaltar a construção da infância da época, devido aos enredamentos históricos que permeiam o sujeito criança silenciado, significado pela etimologia da palavra, provido do latim, infantǐa ou infante, que significa, aquele/a que não tem fala. (MICHAELIS, 2021)
} 
ressignifica o seu corpo, pois agora, segundo ela, é propriedade verdadeiramente sua. Ao invés de sentir objetificada constantemente pelo outro, todas as vezes que tentava comprar uma roupa, vestir um sapato ou sentir-se confortável, torna-se a partir de então, mediadora de si e do mundo. Neste instante, o termo ser para o outro designado por Sartre (2015) é visto em um plano reflexivo. Para o existencialismo sartriano, este conceito caracteriza ontologicamente nossa relação com outro, este que é visto e visado por nós, podendo ser cerceador ou viabilizador de minha liberdade em situação. Compreender o outro como sujeito que está no mundo junto, mas, não é responsável pela concretização do meu projeto, é avizinhar-se da reflexividade.

\section{Segundo momento: a escolha como uma ação política}

Ao percorrer pela sua história em setting, F. desponta sua narrativa em lágrimas, pela intensidade manifestada pelos seus gestos, que se torna um recurso de expressão da atenuação de seu sofrimento. Um fenômeno que repercutiu em seu existir é a morte experienciada ao lado de seu primeiro marido. Na primeira sessão, F. sutilmente menciona sobre sua indignação frente ao tabu da morte em sociedade e menciona a sua fúria em estar inserida em um contexto social com tantas fragilidades éticas e morais. Todavia, é pela oitava à décima primeira sessão, que se adentra em contato com a sua experiência de viuvez.

F. viveu ao lado de John por quatro anos casados. Com ele, pôde realizar sonhos, concretizar projetos (como andar de avião, construir uma moradia). Contar com a morte não fazia parte dos seus projetos. John vem a falecer de gripe $\mathrm{H}_{1} \mathrm{~N}_{1}$, permanecendo algumas semanas na UTI. Frank se viu viúva de seu primeiro casamento e irreconhecível pela experiência de enlutamento, ter bagunçado todo um mundo antes construído conjuntamente. É o que Sartre (1938/1998 p. 24) manifesta pelo personagem Ibbieta, ao deparar-se com a condenação à morte, "havia passado o tempo todo a fazer castelos a eternidade”.

Freitas (2018) afirma que a abruptalidade da perda ou pathos ${ }^{6}$ que ela desponta, implica na impossibilidade de compartilhar projetos com o outro, de reconhecer-se novamente no brilho dos olhos do outro e de fazer-se em um mundo compartilhado. A perda mobilizou Frank a ponto de não se reconhecer como antes. Na décima terceira sessão, ela narra sobre as suas tentativas de suicídio.

Fukumitsu (2013) ampara a significação da tentativa de suicídio como uma atitude em relação a própria vida e por conseguinte a morte, pela violência, que pode ser movimentada a partir das feridas demarcadas pelo contexto social e singular. Fukumitsu (2013) desmembra a palavra ferida, como fé(r)ida, para dar ênfase ao um processo de perda de esperança, de (des)crença na própria existência enquanto

\footnotetext{
${ }^{6}$ Palavra de origem grega para paixão ou sofrimento
} 
alternativa para resolução de problemas. Frank não efetiva a própria morte devido à preocupação com a mãe e após esses episódios, há outras tentativas com a utilização de medicamentos.

Simultaneamente, seu pai rompe sua relação com ela e sua mãe. A usuária vive o desmoronamento de uma imagem construída a partir de uma ilusão de infância, que na vida adulta, não restou nada além de um vazio existencial. Frank disse ter tentado o suicídio por uma exaustão desmedida, por uma dor que perpassou todo o seu corpo, sufocando a garganta, embargando as palavras e os pedidos de ajuda. A dor vinha de dentro pra fora, com o sentimento de (des)esperança, com desejo de findar a própria vida e ao mesmo tempo, o medo de alguém a matá-la.

Com isso, F. recorda-se do dia em que seu pai a expulsou e sua mãe de casa. Recorda-se ter caído de joelhos no chão marrom, barrento do sítio em que estavam situadas no momento e pede auxílio à Clark, seu atual companheiro, para encontrar moradia. Duas semanas após, sua sobrinha solicita sua ajuda devido à uma situação de abuso gerado pelo seu padrasto. A sobrinha e sua mãe vão morar junto a ela. Como a realidade vem toda junta enquanto fenômeno ${ }^{7}$, F. comenta do seu desgaste diante das profissões que teve nessa época e busca, após a sua saída do concurso e de todos os outros trabalhos que teve, fazer algo que fosse significativo, que pudesse ser uma ocupação geradora de impacto nas pessoas.

F. expressa que mudou sua relação com a mãe, hoje, sendo dependente dela devido às condições físicas geradas pelas metamorfoses do seu envelhecer. Vê a mãe a partir de uma cuidadora, visto que com os seus sessenta e seis anos, demanda de Frank uma atenção mais focal. Ao escolher acolher sua mãe após o abandono de seu pai, a usuária relata que não mais se sente como filha e sim, como cuidadora. Além disso, outro papel se reconfigura com o advento da sobrinha. Hoje se vê como mãe, devido ao papel que a sobrinha atribui a ela. Verifica-se que tais papeis delineados pelo o outro é, por F., legitimado em seu fazer-se no mundo.

Essa relação de cuidado, por outro lado, faz com que Frank duvide do futuro (“será que elas ficarão bem quando eu não estiver mais aqui?"(sic)), de suas ações ("tenho medo de criar meu próprio negócio e sair do auxílio porque tem gente que depende de mim" (sic)) e no prosseguimento em seu projeto profissional ("mas, a minha mãe precisa de mim e a minha sobrinha também" (sic)).

Em psicoterapia, Frank significa como resolução de seus conflitos o ato de existir, mesmo que ainda haja a necessidade de auxílio psiquiátrico para conseguir

\footnotetext{
${ }^{7}$ A compreensão da realidade como algo não cindido da experiência humana no mundo permeia as leituras existencialistas por fazerem crítica ao modo cartesiano de apreender o conhecimento. Este debate é mais detalhadamente teorizado por Schneider (2020), em seu estudo recente sobre o método fenomenológico empregado por Sartre e Heidegger, suas convergências e distinções.
} 
"Aprendi com as primaveras a deixar-me cortar e voltar sempre inteira": o caso de Frank

diminuir a intensidade do seu cansaço (que ainda é recorrente) e de suas alterações de humor, pensando em um amparo multiprofissional psi.

A partir dessas falas duvidosas de si mesma e de seu fortalecimento, vinham ao longo das sessões, mais precisamente da décima quinta até o término das sessões, frases que manifestavam outros posicionamentos como: "não sou obrigada (sic)"; "eu posso dar conta das coisas que me acontecem (sic)" e ainda, trechos que a usuária encontrava nas redes sociais, como trechos de poesia: "aprendi com as primaveras à deixar-me cortar e a voltar sempre inteira" ${ }^{8}$, referenciando a sua tatuagem de flor no pulso esquerdo.

Problematizou-se em orientação, até que ponto tais frases estavam sendo acolhidas pela própria usuária enquanto seu movimento de lançar-se ao mundo e aos próprios projetos, visto que durante toda sua vida ela aprendeu a silenciar suas verdades. Como é escutar seus silêncios? Como construir-se novamente em meio ao caos?

Esses questionamentos nortearam as devolutivas, pensando que o tracejar de cada escolha, sendo ela provida pelo cogito, pelo imaginário ou pela reflexividade, crava marcas na biografia do sujeito (SARTRE, 2016). O caos tornou-se necessário para vislumbrar um projeto original, escrito por Sartre (2015) como uma ação genuína em meio à situação, provida de seus desejos. Com isso, na décima oitava sessão que coincidiu com seu aniversário, entrego as frases coladas em bombons, cujo o intuito manifestado em sessão, era de que o presente para celebrar sua vida, nesse processo, em ressignificação, seria suas próprias palavras.

Um outro ponto levantado em psicoterapia a partir da décima sessão, é a construção de seu projeto de ser mulher, teorizado por Beauvoir (2016) como seu fazer-se no mundo em enfrentamento às determinações do patriarcado. Por muito tempo, acreditou ser igual aos ensinamentos do pai por ter sido criada por ele, por conviver no mesmo espaço, pertencer a mesma tipologia sanguínea, ter traços semelhantes e outras características fisiológicas. Diante disso, sentia raiva, ódio por pertencer a um projeto construído para ela e não por ela, tendo em vista todas as esferas que caracterizam a situação, serem fatores limitantes de suas escolhas na época. A partir disso, em psicoterapia, problematizamos quem é este pai nesse momento e quem F. está se tornando, dissociando do sujeito que a fez para a sua autonomia de ressignificar sua própria existência.

F. sente uma decepção desmedida por ver hoje que o pai herói foi o vilão que esperava por salvamento nos dias difíceis, mas, como ela comenta, "eu mesma me salvei nessa história" (sic). O que restou do pai foram os conjuntos de verdades sobre certo/errado, mal/bom que F. carrega consigo e que ao entrar em contato com eles, fortaleceu-se para agir nos trâmites do divórcio de seus pais. Na vigésima segunda

\footnotetext{
${ }^{8}$ MEIRELES (2001).
} 
sessão, F. relata emocionada sobre seu pai ceder e assinar os papéis do divórcio devido aos seus argumentos, apontando que pensava em desistir de seus próprios direitos. Eis nuances do seu projeto de ser mulher, que pôde transcender ${ }^{9}$ uma situação de 40 anos atrás. A partir disso, há um novo ponto: se fragmentos de valores restaram do pai, o que restou de F? quem é F? Com base nisso, realiza-se a Dinâmica do Quadrado.

A usuária em todo instante, firmava-se em seu quadrado, não importasse a intervenção, seja uma tentativa de invadir seu espaço empurrando-a, negociando ou dissuadindo. Ao final, há a devolutiva de quem ela anda se fazendo pela sessão. A devolutiva seguiu-se da seguinte maneira: "F., você pode pensar e até mesmo duvidar da sua força, mas quando se trata de você, das suas verdades e valores, você é essa que enfrenta, que não permite que o outro adentre ou modifique quando se sente ameaçada, você é essa que faz alguma coisa. Não é a vítima da situação. O que falta para que você acredite na força que você tem? Para quê sustentar tantas dúvidas sobre a sua própria capacidade de enfrentar as adversidades da sua vida?" (sic)

Ora, em vários momentos ao longo de sua história, Frank se menciona enquanto espectadora, mas e atualmente? Ao confrontá-la com essa espécie de má-fé, em sessão, levantou-se reflexões a partir da dialética e do imperativo de escolher frente à sua liberdade, ou em outras palavras, como reitera Erthal (1998) do que ela fazia de si mesma frente ao que já foi feito, frente a um passado irrepetível que ela prossegue justificando ao invés de ressignificar.

Outro ponto levantado pela quinta sessão, foi uma relação conflituosa com a sogra, pois, após o abandono de seu pai, foi morar junto com sua mãe e sobrinha na casa da família de Clark. Todavia, houveram desavenças com sua sogra devido a um choque de cultura (origem japonesa e costumes familiares segregativos) e de valores com F. A dinâmica da Cadeira Vazia, deu vazão ao que desejava falar em todos os momentos que não pôde. Segue a descrição da experiência:

"Eu só não quero disputar, nunca, e não quero disputar o lugar dela na vida do Y...(choro). Eu tenho sentimento por ele de mulher, não quero... que ela me veja como uma... uma disputa porque eu não quero ser mãe dele. [respira fundo e chora]. Eu não quero... que ela se sinta obrigada a me ver como uma pessoa boa... mas eu só quero que me respeita como eu sou. [silêncio e choro]. Eu não sou uma pessoa que talvez você idealizou pra ser a esposa do seu filho. [silêncio, choro, respiração funda]. Mas eu não vou e não preciso mudar a minha personalidade, o meu caráter para te agradar! Eu não vou fazer isso! [silêncio, choro e respiração funda]. Respeito eu sempre tive, e sempre vou ter, eu vou sempre vou respeitar, mas não vou mudar, ser outra pessoa

\footnotetext{
9 Este termo encontra-se no ensaio $O$ segundo sexo de Simone de Beauvoir para designar a ação que impacta na contramão do projeto do patriarcado de um sujeito fêmea asujeitada, inessencial e marionete dos anseios do detentor de sua liberdade. Como uma reflexão crítica sobre o percurso de enfrentamento feminino no mundo patriarcal, Beauvoir (2016) escreve que, o processo do nascimento da mulher livre ainda está em processo e luta.
} 
“Aprendi com as primaveras a deixar-me cortar e voltar sempre inteira": o caso de Frank

pra agradar porque eu não sou assim, a minha personalidade não me obriga a ser assim, eu não concordo isso na minha vida, ter que fazer coisas para agradar pessoas, também não concordo com atitudes suas! Mas nem por isso eu quero que você mude a sua pessoa pra me agradar, eu só quero que me respeite! Que realmente me respeite! [respiração funda e choro]... eu acho que é só isso" (sic).

Em sessão, F. defrontou-se com um diagnóstico psiquiátrico de depressão e ansiedade, que pensava ser um aglomerado descritivo de sintomas, mas, tinha suspeitas de que isso vinha desde sua infância. Construímos juntos tal experiência de pathos, que perpassa a época de sua vida que ela se descobriu silenciada. Em nexo com um presente, cheio de intensos acontecimentos de sua vida (abandono do pai, a guarda da sobrinha em situação de abuso, ir a outro país ou dar chance ao relacionamento anterior), esse silêncio se fez som por meio do berro, do choro, das crises. Ao movimentar-se pela sua história, percebe que esse sofrimento vem crescendo desde a primeira vez (e em outros momentos de sua vida) que desejou uma atitude de outrem: sua mãe no casamento, a atitude de sua sogra no velório, atitude do pai por abandoná-la. Como Schneider (2009) reafirma: a psicopatologia faz sentido pela tessitura da vida, não em vácuo explicativo de sintomas, mas, pelas entranhas da compreensão a partir da experiência humana no mundo.

F. hoje se coloca no lugar de alguém que é pró-ativa para tudo e todos, e isso é uma forma de reagir frente a um projeto de ser mulher hoje. Todavia, simultaneamente, ainda resta uma suposta vitimização e a má-fé. A vitimização vem das incertezas diante da sua própria força em enfrentar novas situações-problema. Já a má-fé, parte de um conceito de Sartre (1943/2015), caracterizado como uma apreensão irreflexiva de escapar da liberdade e do imperativo de escolher e, por consequência disso, em arcar com as responsabilidades de seus atos, nesse caso, de esperar do outro uma iniciativa que ela faria, aniquilando a liberdade do outro. Ao ver que o outro não corresponde às ações esperadas, Frank se prontifica e "vai lá e faz" (sic), cansando-se e impedindo por outro lado, o outro de fazer-se no mundo.

Isso fica claro quando não permite que sua sobrinha trace os seus próprios projetos de independência, ou quando se sente na responsabilidade de ser cuidadora eterna dela e de sua mãe. Como Schneider (2007) aponta, a psicopatologia deve ser reconhecida a partir do momento em que a nomeada "loucura" afeta o devir humano, definhando a sua possibilidade de traçar projetos. Baseado nisso, é que durante as sessões fomos compreendendo o seu diagnóstico a luz de sua biografia, que envolvem muito além de um conjunto de sintomas, mas, um aglomerado de experiências, haja vista ter sido silenciada (depressão) e agora, poder agir e querer agir a todo custo (ansiedade). A infância de Frank correspondeu ao que Schneider (2008) aponta como cogito ou saber-de-ser: uma pessoa que por muito tempo foi silenciosa e silenciada.

Na contramão de tanta inércia diante daquilo que considerava errado ou injusto, F. decide ser uma pessoa "que vai lá e faz acontecer" (sic), continente, isto é, que dá 
conta de tudo e todos a sua volta, cruzando a fronteira da generosidade e do engrandecimento, sem pensar nas repercussões de seus atos. Acolhe a mãe, a sobrinha, vai ao encontro dos problemas do seu atual parceiro, da família do parceiro, deseja ser aceita pela sua sogra, deseja que todos os seus projetos se concretizem. Em meio a tantos desejos, encontra-se em um enorme cansaço e esbarra com os seus limites, visto que acolhe a todos, menos a si própria e as escolhas condizentes ao seu projeto de ser. Debruçar-se sobre este cansaço, permitiu a F. apreender, pela reflexividade, o seu atual estado de esgotamento e o que fazer com isso.

Ao mencionar seu projeto, ao longo das sessões, problematizamos o que a motivou sair da sua profissão anterior e o que hoje, em sua atual conjuntura, consegue fazer para ressignificar seu percurso no mercado de trabalho. Como Beauvoir (1949/2016) já reiterou no final da década de 40, há diferenças em relação às determinações que rondam a mulher e algumas destas, relatadas pela usuária, foram: a questão da reificação do seu corpo pelo seu próximo, assédio moral e sexual e da explícita vivência de desigualdade de gênero no espaço de trabalho, caracterizando o lugar e seus arredores.

Em meio a isso, Frank decide sair do emprego e desde a sua decisão, fazem três anos que não está mais atuante no mercado de trabalho. Realiza cursos, experimenta novos segmentos de emprego e atualmente, se identifica com que faz (mesmo não tendo planejado ser cabeleireira), todavia, há impedimentos em relação à sua insegurança em agir frente ao futuro e a sua imprevisibilidade, o medo de assumir uma nova profissão, muitas vezes justificada pela dificuldade em cuidar de sua mãe e de sua sobrinha. Na penúltima sessão, F. relata que uma das profissionais do INSS, órgão amparador de sua condição econômica atualmente, havia sugerido um novo curso relacionado ao segmento da estética de sua preferência. F. hesita e pergunta se realmente está pronta. Problematizamos então, o que ela espera de uma profissão? Quais impedimentos são esses que distanciam ela de um recomeço?

Tais problematizações foram feitas anteriormente pela característica interventiva do livro A parte que falta $(1976 / 2018)$ e disparadora de maiores questionamentos como: o que me falta para trilhar meus caminhos? Será o vazio algo ruim $^{10}$ ? Para quê sigo buscando a completude como critério de realizar meus projetos?

$\mathrm{Na}$ última sessão, ela acrescenta que para todas as perguntas - além das formuladas em sua cabeça, como costuma dizer - as respostas estão nas experiências. F. permitiu-se vivenciar o curso ${ }^{11}$. Percebe que não sente desejo de abrir um próprio

1o O vazio é designado quando há a ausência de respostas para o curso de existir e para o existencialismo, o sujeito é livre, no sentido de não haver determinações ou verdades que redigem as ações humanas no mundo. Em psicoterapia, o vazio é oportunidade de redescobrir o sentido guiado verdadeiramente pelo desejo do sujeito, nas vias reflexivas de como ele aparece, pensando nas alienações que repercutem no processo de subjetivação (ERTHAL, 1995).

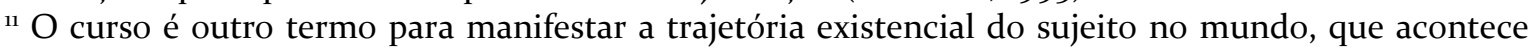
dialeticamente com a história, pelo que foi vivido, a percepção do vivido e do que poderá ser 
empreendimento, mas, pretende adquirir técnica trabalhando em salões e seu projeto de fazer algo significativo enquanto trabalho prossegue. Sobre o divórcio, entende que é a ponta do iceberg e agora, os enfrentamentos serão mais intensos, todavia, reconhece prévias de sua força para resolução de conflitos. Ao final, há o encerramento do processo psicoterápico devido ao fim do ano letivo e o encaminhamento para psicólogos conveniados para suporte nas férias e para a continuação da psicoterapia no CPA no ano seguinte.

\section{Considerações finais}

$$
\begin{array}{r}
\text { "no fundo, no fundo, } \\
\text { bem lá no fundo, } \\
\text { a gente gostaria de ver nossos problemas } \\
\text { resolvidos por decreto } \\
{[\ldots]} \\
\text { mas problemas não se resolvem, } \\
\text { problemas têm família grande, } \\
\text { e aos domingos saem todos passear } \\
\text { o problema, sua senhora } \\
\text { e outros pequenos probleminhas" } \\
\text { (LEMINSKI, p. 2013 p. 195) }{ }^{12}
\end{array}
$$

Tal como Paulo Leminski expressa em sua poesia, a procura pelo serviço psicológico surgiu pela necessidade da usuária em resolver um conflito relacionado aos seus transtornos de humor, o que em um primeiro momento, tinha-se uma compreensão difusa e limitada. Pelo caminho psicoterápico, esbarramos em uma busca incessante de enfrentamentos, de reconfiguração de sentidos frente a vários de seus problemas, que por algum tempo foram efetivos e em outros momentos, necessitarão de novos traços subjetivos, outras rotas e problematizações frente às novas questões que surgiam.

No desenrolar das vinte e três sessões, Frank defrontou-se com várias questões existenciais que pôde ressignificar e que foi possível de compreensão (e nesse formato, explanação e teorização) pelo método proposto por Sartre (1943/2015) e seus comentadores. A primeira delas, foi o seu projeto de ser mulher. Desde a infância, foi a menina que esperava da mãe uma ação, do pai criava uma imagem de herói, dos outros desejava um certo amparo frente à sua construção de vida. Apesar disso, a usuária vivenciou o apequenamento de seu ser, ao tentar agir, no que repercutiu em seu corpo e no seu relacionar-se com o outro.

Pela consciência reflexiva, Frank pôde apreender que não é mais a criança que desejava em silêncio por uma ação. Ela "adultesceu" em uma temporalidade que caracteriza seu projeto e hoje, consegue perceber-se agindo frente situações que fora

modificado. A dialética faz este vai e vem com o passado, pois, as mudanças partem da contradição e do enfrentamento da repetição da história (FREITAS, 2018).

${ }^{12}$ Itálico nosso. 
silenciada e isso, repercutiu na força que mantém suas escolhas como no prosseguimento do divórcio, no seu fazer-se independente do pai e do cuidado com a mãe após o abandono e do trato com a sobrinha. Nota-se uma ressignificação dos lugares, do passado e dos objetos, pois, F. compreende tais aspectos enquanto características que contornam o ser que ela é hoje, mas, estes, não se tornam subterfúgios para estar estanque, pois, ela pode ultrapassar suas determinações, ou seja, agir.

Nisso, a força advinda da experiência vivida é o que intensifica o seu projeto de ser mulher hoje, vendo seu corpo como instrumento mediador de si e do mundo e além disso, como sobrevivente das vicissitudes, como objeto que manifesta marcas e motivos para existir. A frase inaugural desse novo projeto de F. (e que inspirou o título desse artigo) é da Cecília Meireles (1963/2001), utilizada pela usuária: “Aprendi com as primaveras a deixar-me cortar e voltar sempre inteira". O sentido de ser podada, cortada, advém das intensas determinações que o outro implicou à usuária, principalmente, em um existir repleto de perdas de entes queridos, de sentido e de amparo familiar. Todavia, o que nos respaldou em processo psicoterápico, foi a angústia de voltar apesar das marcas e ausências, isto é, como fazer-se inteira novamente. Nada mais é do que o processo dialético: cortar e reconstruir-se, ser produto e produtor de seu meio.

Na tentativa de dar uma chance para quem ela será, a usuária olha para as suas marcas e diz ser a prova corporal de tentar fazer-se frente àquilo que os outros fizeram dela (estigma social, violências frente ao seu corpo obeso, desigualdade de gênero, etc), visto que viver não possui nenhum sentido, a não ser que, prossiga a fazer suas escolhas no mundo. Isto é o que Sartre (1946/2014) fundamenta em sua filosofia existencial e o que contornou os rumos terapêuticos desse caso clínico: a liberdade enquanto condição humana que rompe determinismos a luz dos sentidos que o existente atribui em seu existir, baseado no vazio, isto é, nas possibilidades e ressignificações escolhidas autenticamente.

Com relação à sua atitude de ser continente, visto pela obrigatoriamente em ser a pessoa que dá conta de tudo e todos, nota-se que tal atitude acontece irreflexivamente, e por consequência disso, F. negligencia os seus próprios limites e a liberdade do outro em arcar com as suas próprias repercussões ao fazer-se no mundo. É notória a sua pressa de viver e de reconhecer seus problemas, tal como Leminski aponta, resolvidos por um decreto, movimentado pela sua experiência de ansiedade. A relação de Frank com a pressa e o tempo dos projetos continua a ser um aspecto que ela terá de lidar de forma multidisciplinar, com os esforços conjuntos dos profissionais psi e de si mesma.

Devido ao encerramento do período de estágio supervisionado curricular específico obrigatório, há pontos que poderiam ser desenvolvidos, mesmo frente aos avanços da usuária, que fazem nexo com a sua insegurança e medo. A insegurança 
diante do incerto é o que ainda imobiliza Frank em de fato concretizar a possibilidade de uma outra profissão, mesmo com a validação de sua força e capacidade frente ao novo. Sentir-se pertencente a este novo território existencial de ação e segurança é o que escapou no processo psicoterapêutico, devido ao tempo do curso dos atendimentos e da usuária.

Além disso, o medo em seguir seu projeto é justificado pela dependência dos outros (mãe e sobrinha), explicitamente caracterizado pela má-fé, devido ao fato de desviar da responsabilidade dela (e dos outros) em existir. Fazer diferenciações entre cuidado e controle, ação e tempo, levando em conta o seu próprio movimento no mundo, dado ao entendimento que não somos legisladores de mudanças, são pontos que necessitam ser retomados para auxiliar no fortalecimento da concretização de seu projeto profissional, conjuntamente com os sintomas de depressão e ansiedade.

\section{Referências}

ALVIM, M. B.; CASTRO, F. G. de. "O que define uma clínica de situações contemporâneas? Apontamentos a partir de J-P. Sartre e M. Merleau-Ponty”. In: Alvim, M. B. (org.). Clínica de situações contemporâneas: fenomenologia e interdisciplinaridade. Curitiba: Juruá, 2015, p. 1547 .

BEAUVOIR, S. de. O segundo sexo: a experiência vivida. Tradução de Sérgio Milliet. 3. ed. Rio de Janeiro: Nova Fronteira, 2016.

CAMPOS, S. S.; FERREIRA, F. R.; CARVALHO, M. C. V. S.; KRAEMER, F. B; SEIXAS, C. M. "O estigma da gordura entre mulheres na sociedade contemporânea". In: PRADO, S. D.; AMPARO-SANTOS, L.; SILVA, L. F.; AMATZ, M. G.; BOSI, M. L. M (orgs.) Estudos socioculturais em alimentação e saúde: saberes em rede. Rio de Janeiro: EDUERJ, 2016. p. 231249. Disponível: <http://books.scielo.org/id/37nz2/pdf/prado-9788575114568-12.pdf> Acesso em: 26 ago. de 2019

CONSELHO FEDERAL DE PSICOLOGIA (CFP). Código de Ética Profissional do Psicólogo: Promulgado em 21 de julho de 2005. Disponível em: <https://site.cfp.org.br/wpcontent/uploads/2012/o7/Código-de-Ética.pdf> Acesso em 30 agosto de 2019.

ERTHAL, T. C. S. Treinamento em psicoterapia vivencial. Petrópolis: Editora Vozes, 1995.

FREITAS, S. M. P. de. "O caminho dialético e heurístico para a construção do conhecimento”. In: FREITAS, S. M. P. de. Psicologia existencialista de grupos e mediação grupal: contribuições do pensamento de Sartre. $1^{\mathrm{a}}$ ed. Curitiba: Appris, 2018, p. 109-138.

FREITAS, S. M. P. de. "Uma análise existencialista para um caso clínico de transtorno obsessivo compulsivo". Revista da Abordagem Gestáltica, v. 17 n. 2, p. 205-214, 2011.

Disponível em: <http://pepsic.bvsalud.org/pdf/rag/v17n2/v17n2a12.pdf> Acesso em 17 abr. 2019.

FREITAS, J. L. "Luto, pathos e clínica: uma leitura fenomenológica". Psicologia USP, v. 29 n.1 p. 50-57, 2018. Disponível em: <http://www.scielo.br/pdf/pusp/v29n1/1678-5177-pusp-29-o150.pdf > Acesso em 02 abr. 2019:

FUKUMITSU, K. O. O processo do luto da pessoa que cometeu suicídio. (Tese de Doutorado) - 237 f. Instituto de Psicologia da Universidade de São Paulo - IP USP, São Paulo, SP. 2013, Brasil. Disponível em: <https://www.teses.usp.br/teses/disponiveis/47/47131/tde-04072013143625/publico/fuku_corrigida.pdfs Acesso em 02 set. 2019. 
LEMINSKI, P. “Distraídos venceremos”. In: LEMINSKI, P. Toda Poesia. São Paulo: Companhia das Letras, 2013 p. 167-231.

MEIRELES, C. Antologia Poética. Rio de Janeiro: Nova Fronteira, 2001.

MENDES, J. P. S.; GRESSLER, S. K. A. B.; FREITAS, S. M. P. “Ser psicoterapeuta: reflexões existenciais sobre vivências de estagiários-terapeutas iniciantes.” Revista da Abordagem Gestáltica. v. 18 n. 2 pp. 136-143, 2012 Recuperado em 17 abril, 2019 $<$ http://pepsic.bvsalud.org/scielo.php?script=sci_arttext\&pid=S180968672012000200003>.

MICAELIS. Dicionário Brasileiro de Língua Portuguesa. "Páthos: definição". Disponível em: $<$ https://michaelis.uol.com.br/busca? $\mathrm{r}=\mathrm{o} \& \mathrm{f}=\mathrm{o} \& \mathrm{t}=\mathrm{o} \&$ palavra=p\%C3\%Arthos $>$ Acesso em 15 fev. 2021.

SARTRE, J. -P. O existencialismo é um humanismo. Tradução de João Batista Kreuch. 4. ed. Petrópolis, RJ: Vozes, 2014

O ser e o nada: ensaio de ontologia fenomenologia. Tradução de Paulo Perdigão. 24. ed. Petrópolis, RJ: Vozes, 2015.

. O muro. Tradução de H. Alcântara Silveira. Rio de Janeiro: Nova Fronteira, 1998

SCHNEIDER, D. R. "O Método biográfico em Sartre: contribuições do existencialismo para Psicologia." Estudos e Pesquisa em Psicologia. v. 8 n. 2 pp. 289-308, 2008. Disponível em: $<$ http://pepsic.bvsalud.org/pdf/epp/v8n2/v8n2a13.pdf> Acesso em o4 agosto, 2019.

"Caminhos históricos e epistemológicos da psicopatologia: contribuições da fenomenologia e existencialismo." Cadernos Brasileiros de Saúde Mental, v. 1 n. 2 p. 62-76, 2009. Disponível em: <http://psiclin.ufsc.br/files/2010/o4/SCHNEIDER-D.-Caminhos-histe-epist.pdf $>$ Acesso em 29 maio, 2019

"Fenomenologia de Heidegger e Sartre em suas diferenças." Revista Aufklärung Esp v. 7 s/n, pp. 77-92, 2020. Disponível em:

<https://periodicos.ufpb.br/index.php/arf/article/view/50293> . Acesso em 16 de jul. de 2020.

SILVA, C. A. F. "O brotar originário da liberdade: Sartre e a existência radical”, in ECOS Estudos Contemporâneos da Subjetividade, v. 8, p. 221-227, 2018. Disponível em: http://www.periodicoshumanas.uff.br/ecos/article/view/2856.

“Aportes clínicos sartrianos III: método progressivo-regressivo”. In: aufklärung: revista de filosofia, v. 7, p. 137-150, 2020. Disponível em:

https://periodicos.ufpb.br/index.php/arf/article/view/50529 DOI:

https://doi.org/10.18012/arf.2019.50529

SILVA, L. C. de.; VACCARO, M. M. "A constituição do sujeito: uma reflexão a partir de JeanPaul Sartre.” Revista de Psicologia. v. 7 n. 2., 99-109, 2016. Disponível em:

$<$ http://www.periodicos.ufc.br/psicologiaufc/article/view/6278/4496> Acesso em o3 junho, 2019

SILVERSTEIN, S. A parte que falta. Tradução de Alípio Correia de Franca Neto. São Paulo: Companhia das Letrinhas, 2018.

VACCARO, M. M. Constituição do Sujeito e Historicidade: um estudo a partir do existencialismo sartreano. (Dissertação de Mestrado) - $101 \mathrm{f}$., Universidade Estadual de Maringá - UEM, Maringá, PR, 2014, Brasil. Disponível em:

$<$ http://www.ppi.uem.br/arquivos-para-links/teses-e-dissertacoes/2014/marinamene> Acesso em 15 fev. 2021. 
"Aprendi com as primaveras a deixar-me cortar e voltar sempre inteira": o caso de Frank

Submissão: 15. 02. 2021

/ Aceite: 30. 10. 2021

98 